\title{
Author reply
}

\author{
Shahin Akhondzadeh • Raofeh Ghayyoumi
}

Received: 10 December 2010 / Accepted: 14 December 2010/Published online: 8 January 2011

(C) Springer-Verlag 2011

\section{Dear Editor,}

We thank Dr. Gaurrav N. Kaushik for his letter. As we described in our study, pharmacological, anatomical, and genetic information indicate that deficits in glutamatergic neurotransmission, particularly those mediated by NMDA receptors, may be a contributor to all three symptom clusters (Akhondzadeh 1998). Although reduced corticostriatal transmission may specifically contribute to an apparent hyperdopaminergia and psychotic symptoms, the downstream consequences of such a disruption may also contribute to the negative and cognitive symptoms of schizophrenia (Noorbala et al. 1999). Indeed, Siuciak concluded in their review that PDE inhibitors "may be effective in treating positive symptoms, negative symptoms and/or cognitive deficits associated with schizophrenia" (Siuciak 2008). Therefore, based on these points, Goff et al. and our study focused on negative symptoms as well (Goff et al. 2009). In addition, as we explained in the method of our study, we excluded the patients with depression. The
PANSS depression item score (exclusion level $\geq 4$ ) was used to exclude patients with significant levels of depression. Therefore, the possible antidepressant effect of PDE inhibitors is not the important point.

Shahin Akhondzadeh and Raofeh Ghayyoumi

\section{References}

Akhondzadeh S (1998) The glutamate hypothesis of schizophrenia. J Clin Pharm Ther 23:243-246

Goff DC, Cather C, Freudenreich O, Henderson DC, Evins AE, Culhane MA, Walsh JP (2009) A placebo-controlled study of sildenafil effects on cognition in schizophrenia. Psychopharmacology (Berl) 202:411-417

Noorbala AA, Akhondzadeh S, Davari-Ashtiani R, Amini-Nooshabadi H (1999) Piracetam in the treatment of schizophrenia: implications for the glutamate hypothesis of schizophrenia. J Clin Pharm Ther 24:369-374

Siuciak JA (2008) The role of phosphodiesterases in schizophrenia: therapeutic implications. CNS Drugs 22:983-993
S. Akhondzadeh $(\varangle) \cdot$ R. Ghayyoumi

Psychiatric Research Center, Roozbeh Psychiatric Hospital,

Tehran University of Medical Sciences,

South Kargar Street,

Tehran 13337, Iran

e-mail: s.akhond@neda.net 